\title{
AVALIAÇÃO
}

\section{O Exame Nacional de Cursos (ENC)}

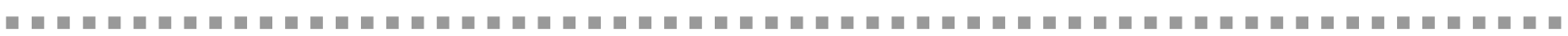

\section{S}

itua o Exame Nacional de Cursos (ENC) como um dos instrumentos de avaliação do ensino superior no Brasil. Descreve o processo de implantação do Exame, apontando seu marco legal. Descreve a sistemática de aplicação do Exame, as provas e os questionários-pesquisa que o integram e a forma como os resultados são organizados, disseminados e utilizados. Aponta as repercussões do Exame junto às instituições de ensino, ao corpo docente, aos estudantes e aos órgãos públicos.
Tancredo Maia Filho Orlando Pilati Sheyla Carvalho Lira

Palavras-Chave: Exame Nacional de Cursos; avaliação do ensino superior.

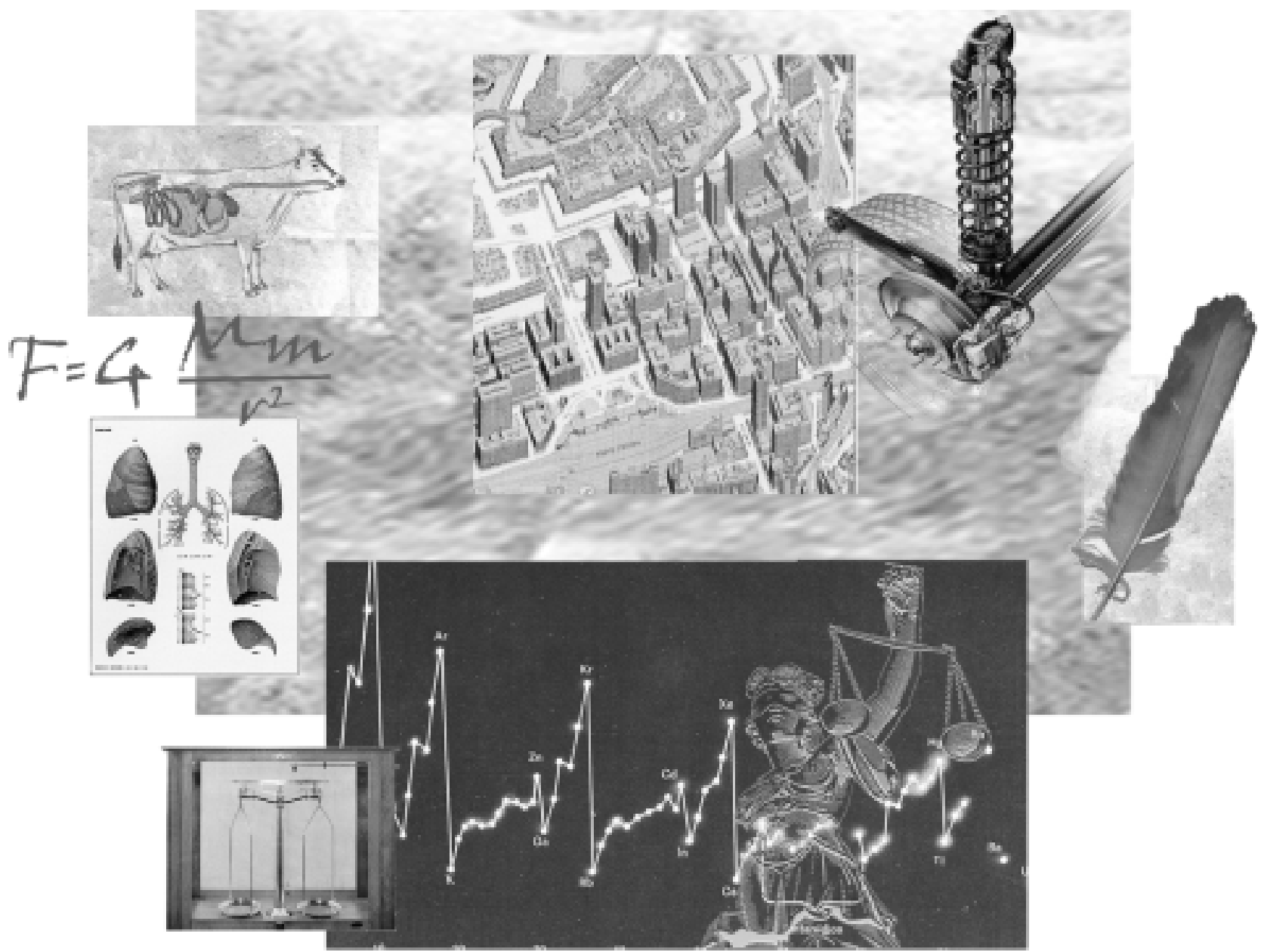




\section{Introdução}

A adoção de processos de avaliação é um procedimento indispensável à melhoria da qualidade do ensino. Por esse motivo, sistemas avaliativos, em todos os níveis educacionais, são cada vez mais difundidos em países em que a educação é prioritária.

Apesar de sua reconhecida importância, as experiências na construção de sistemas nacionais de avaliação de cursos e instituições de ensino superior, principalmente de graduação, são recentes na história mundial. Elas existem em países tão diferentes quanto Austrália, Brasil, Estados Unidos, República Popular da China, Argélia, Inglaterra, Canadá, Japão, Coréia do Sul, Argentina, França e Cuba. Na maioria dos casos, foram iniciadas a partir de 1970. Trata-se de uma atividade em franco processo de desenvolvimento, ora por iniciativa do Estado, ora por mobilização de entidades que congregam as instituições, ora em parceria entre Estado e instituições.

Os sistemas nacionais em construção podem ter maior ou menor abrangência quanto aos objetos e objetivos, pois o contexto político de cada país acaba determinando as diferentes ênfases aos aspectos acadêmicos (produção científica, resultados dos processos de ensino-aprendizagem); aos econômico-financeiros (gerência de recursos, custos, captação de recursos, etc.); e à relação com a sociedade (educação e desenvolvimento social e econômico, mercado de trabalho, etc.). Apesar das diferenças, pode-se dizer que todos, de alguma forma, têm como razão de ser a sua contribuição para as mudanças, para a definição e a retroalimentação de ações gerenciais ou de políticas institucionais e estatais voltadas para a melhoria da qualidade tanto do ensino superior como da produção do conhecimento.

O caráter político da avaliação na educação superior advém desse seu compromisso com a mudança, com o desenvolvimento do que é incipiente, mas que se revela como fundamental para a reafirmação e a consolidação de aspectos relacionados às prioridades sociais em termos de conhecimento e tecnologia. Quando isto não ocorre, os sistemas de avaliação podem reduzir-se a meros processos estáticos de gestão e controle que não extrapolam as estruturas burocráticas das instituições e do Estado.
O Exame Nacional de Cursos (ENC), ao se propor a verificar o êxito do processo de ensino-aprendizagem no tocante aos aspectos relacionados à aquisição e à aplicação de conhecimentos e habilidades básicas dos concluintes dos cursos de graduação, permite, pela primeira vez na história do ensino brasileiro, uma avaliação dos resultados do trabalho desenvolvido por esses cursos, na perspectiva apontada.

O processo de avaliação do ensino superior, embora bastante complexo e diferenciado, é particularmente necessário, em virtude da multiplicidade de funções que preenche e da diversidade dos cursos oferecidos. Isso se deve ao papel cada vez mais relevante que a educação superior vem assumindo no mundo moderno, especialmente em virtude de sua função estratégica para o desenvolvimento tecnológico, econômico, social e cultural de uma nação.

A importância da avaliação do ensino superior não se limita ao seu potencial para a elaboração de diagnóstico. Ela é instrumento capaz de contribuir para o conhecimento da realidade dos cursos e, a partir daí, estimular a reflexão sobre o presente, as aspirações futuras e catalisar as discussões sobre o caminho a trilhar, o modelo desejado e as estratégias para a construção desse modelo.

\section{Antecedentes}

O Brasil foi o primeiro país da América Latina a instituir processos de avaliação na educação superior, começando pela pós-graduação. A pesquisa tem sido objeto de procedimentos sistemáticos de avaliação nos órgãos governamentais de fomento, tais como o Conselho Nacional de Desenvolvimento Científico e Tecnológico (CNPq) e alguns órgãos estaduais de pesquisa, especialmente em São Paulo, Rio de Janeiro, Rio Grande do Sul e Minas Gerais.

O único sistema nacional de avaliação institucionalizado existente que envolve não apenas a pesquisa era, até recentemente, entretanto, o "sistema de avaliação dos cursos de pós-graduação" da Fundação Coordenação de Aperfeiçoamento de Pessoal de Nível Superior (Capes). Iniciou-se na década de 70 e esteve relacionado à formulação de ações e polí- 
ticas para o desenvolvimento dos programas de pós-graduação. Esses programas sempre estiveram voltados para a formação e a capacitação de pessoal docente das instituições universitárias e para a atuação nas pesquisas desenvolvidas em órgãos específicos ou nas próprias instituições de ensino. Seu foco de avaliação centrava-se na proposta didático-científica e na produtividade científica e acadêmica de cada curso de mestrado e doutorado em funcionamento.

Uma das características fundamentais desse sistema de avaliação foi a participação da própria comunidade envolvida, por meio de comissões representativas, apesar de ser conduzido pelo Estado. Outro resultado positivo foi a efetiva contribuição dos resultados da avaliação na redefinição de ações ou mesmo na reformulação de diretrizes e políticas para a área. Mas também construiu parâmetros de referência para que cada curso/programa desenvolvesse a sua proposta.

O processo conduzido pela Capes, um órgão governamental, se constitui uma típica avaliação externa, que nunca pretendeu ferir a autonomia institucional e acadêmica. Já na década de 90, a Capes foi transformada em uma Fundação vinculada ao Ministério da Educação (MEC), mas continuou com as mesmas atribuições relacionadas à política da pós-graduação brasileira. Utiliza os próprios pares que atuam nos programas de pós-graduação como os principais atores do processo. Os resultados são produzidos e utilizados segundo o interesse da própria Fundação, enquanto órgão responsável pela política da pós-graduação no país. Mas também servem diretamente aos cursos e às instituições que os oferecem.

Entretanto, nunca se conseguiu implantar um processo semelhante que abrangesse o universo dos cursos de graduação, apesar de várias tentativas. Dentre essas, pode-se citar o Programa de Avaliação da Reforma Universitária, implementado pela própria Capes entre 1983-1985, mas apoiada pela Financiadora de Estudos e Projetos (Finep). Apesar de extremamente abrangente em sua proposta (ou talvez por isso mesmo), a polêmica inicial provocada, os estudos produzidos por membros da coordenação do projeto (Beloni, 1986; Ribeiro et al., 1986a, 1986b; Porto, Veloso, Pilati, 1988) ou contratados pelas instituições participantes, serviram para reforçar a idéia da necessidade de uma avaliação no sistema de educação superior.

Um dos ensinamentos retirados desse programa foi o de que tentativas de avaliação institucional, que tomassem como unidade a instituição e pretendessem, mediante um processo único e completo, medir o seu desempenho em todas as áreas de conhecimento, abrangendo todo o ensino, toda a pesquisa e toda a extensão, seriam por demasiado complexas e quase intermináveis. Os resultados de um processo institucional global de avaliação pareciam ter pouca probalidade de contribuir, em tempo útil, para o seu aproveitamento no processo de ensino-aprendizagem e, simultaneamente, na gestão e/ou na definição de ações indispensáveis para a melhoria da qualidade do ensino de graduação.

Toda avaliação é necessariamente parcial, e nenhuma, por mais completa que seja, pode dar conta da totalidade das variáveis que influem na qualidade do ensino e na sua adequação a contextos sociais e culturais diversos. Começou a sedimentarse a idéia de que a avaliação do ensino superior, em suas múltiplas dimensões e funções, só pode ser feita por meio de um sistema avaliativo que utilize múltiplos instrumentos e procedimentos, de tal forma que as parcialidades próprias de cada processo se complementem.

Direta ou indiretamente, a experiência do Programa de Avaliação da Reforma Universitária deu origem a uma série de experiências institucionais (vejam-se, por exemplo, as primeiras unidades dentro de instituições responsáveis por diferentes atividades de avaliação com relação à própria instituição), bem como de estudos específicos mais abrangentes até o início da década de 1990. A discussão aprofundou-se nas instituições. O próprio ministério formulou uma proposta denominada "Uma Nova Política para a Educação Superior" (1985), produzida pela Comissão Nacional para a Reformulação da Educação Superior, na qual se dava ênfase à avaliação como mecanismo de melhoria da qualidade do ensino superior.

Em seqüência, o Grupo Executivo para a Reformulação da Educação Superior (Geres), constituído em 1986 para detalhar as propostas gerais de uma nova política, alertava que "apesar de a legislação se referir a um controle finalístico das instituições, na prática, controlam-se bu- 
rocraticamente os meios (orçamentos, rubricas, número de docentes, etc.), sem nunca se avaliar o desempenho da instituição em sua multifuncionalidade". $O$ Geres propunha substituir o controle burocrático das instituições de caráter universitário pela constituição de um processo de avaliação conduzido pelo ministério, que deveria "contemplar duas vertentes básicas: a da avaliação do desempenho institucional e a da avaliação da qualidade dos cursos oferecidos. Embora intimamente relacionados, esses dois enfoques são complementares e se utilizam de parâmetros distintos."

O Conselho de Reitores das Universidades Brasileiras (Crub) foi um depositário das discussões amplas provocadas pelas propostas de reformulação da educação superior (Reforma, 1987), mas em sua proposta deu mais ênfase a medidas de curto prazo que pudessem "contribuir significativamente para a melhoria da atividade acadêmica das universidades (principalmente federais) e para o aperfeiçoamento da ação administrativa", entre as quais se destacava a "isonomia entre servidores das universidades autárquicas e fundacionais". Quanto à avaliação, propôs que a supervisão exercida pelo MEC incluísse "procedimentos de avaliação, com a participação da comunidade universitária, que permitam acompanhar o cumprimento dos objetivos institucionais da Universidade e seus compromissos com a sociedade". Apesar dos grandes embates, onde se defrontavam diferentes posições ideológicas e de conceitos a respeito da educação superior, praticamente nenhuma medida concreta se consolidou, embora as experiências continuassem a ocorrer em diversos níveis.

É importante lembrar que essas discussões e experiências inseriam-se no contexto do movimento pela redemocratização da sociedade brasileira, quando, entre outras coisas, se evidenciava que, apesar de a sociedade brasileira continuar reivindicando a expansão do sistema de educação superior, era indispensável construírem parâmetros de qualidade para o ensino de graduação, sob pena de não se produzirem os conhecimentos técnicos e científicos necessários para uma sociedade que se pretendia mais justa.

Pode-se dizer que o Programa de Avaliação Institucional das Universidades
Brasileiras (Paiub), coordenado pela Secretaria de Educação Superior (SESu), surgiu em 1993, como decorrência dos desdobramentos da experiência do Programa de Avaliação da Reforma Universitária, das contribuições das próprias instituições quanto à forma de condução da avaliação institucional e das experiências que vinham sendo feitas desde os anos 80 (Paul, Ribeiro, Pilati, 1992).

A ênfase principal do Paiub está na auto-avaliação institucional voluntária de distintos tópicos, apoiada nas mais diferentes abordagens teóricas e metodológicas. Embora pretenda envolver todos os segmentos da instituição, pode ter abrangência restrita a um setor ou aspecto das múltiplas funções. As instituições participantes propõem-se a trabalhar com indicadores básicos, como forma de garantir uma certa comparabilidade. Numa etapa seguinte, esta auto-avaliação interna pode ser equilibrada pela avaliação externa feita por especialistas interpares das diferentes áreas analisadas.

O controle dessa avaliação está nas mãos de cada instituição que se auto-avalia, cabendo à SESu incentivar o intercâmbio entre as experiências das instituições e a eventual alocação de recursos para o apoio parcial de cada projeto. Uma das características do Paiub é que os resultados dos projetos institucionais podem ser de extrema utilidade para áreas específicas de uma instituição ou para a revisão do seu projeto institucional global. Mas, pela diversidade de abordagens e de amplitude das questões, há dificuldades para a comparação de experiências, alternativas e de resultados institucionais. Limita também a construção de parâmetros referenciais de qualidade, principalmente no que se refere ao ensino de graduação propriamente dito. Mas, a multiplicação das experiências recentes da avaliação, o entendimento de que, em nível nacional e institucional, os sistemas de avaliação devem ser compostos por vários processos avaliativos complementares, bem como os resultados do ENC, realizado a partir de 1996, vêm fazendo com que o Paiub seja revalorizado, como é demonstrado pelo aumento significativo do número de projetos institucionais apresentados à SESu a partir de 1997.

Em 1996, a Fundação Capes promoveu a retomada da discussão da pós-graduação brasileira, com o objetivo de identificar problemas e formular novas ações. Em 
um dos aspectos analisados, Yvonne Maggie (1996) e Cézar Zucco (1996) constataram um fraco compromisso da pós-graduação com a graduação, não gerando melhoria equivalente neste nível. Propõem que, na avaliação dos cursos de pós-graduação, seja considerada também a sua contribuição aos cursos de graduação na mesma área, contemplando aspectos que vão desde a análise dos currículos de graduação até atividades de iniciação científica, monitoria, etc. Mas Maggie alerta também que deveriam ser desenvolvidos processos específicos de avaliação dos cursos de graduação. Dentre esses processos, destaca uma nova alternativa, propondo que "ao MEC poderia ser reservada a avaliação do aprendizado, como já está fazendo para o 1 o e o 2 o graus, com sucesso". ${ }^{1}$ $\mathrm{Na}$ sua visão, esse procedimento garantiria maior espaço para a autonomia, em face da variedade de culturas e ethos institucionais existentes no sistema e, ao mesmo tempo, permitiria o estabelecimento de padrões de qualidade.

A essa altura, já estava criado o ENC, cuja primeira experiência seria realizada em novembro de 1996, com três cursos: Administração, Direito e Engenharia Civil. O Exame, como se demonstrará a seguir, integra um sistema nacional de avaliação da educação superior. Está voltado para o resultado do processo de ensino-aprendizagem nos cursos de graduação. Nesse sentido, vem sendo estruturado como um mecanismo de avaliação externa, complementar aos processos desenvolvidos em níveis nacional e institucional.

\section{Marco legal}

No Brasil, até 1995, a avaliação do ensino superior não contava com nenhum programa de abrangência nacional especificamente voltado para o ensino de graduação, embora houvesse, na pós-graduação, um programa de avaliação já consolidado no meio acadêmico e implementado pela Fundação Capes.

A Lei no 9.131, de 24 de novembro de 1995, estabeleceu que fossem realizadas avaliações periódicas das instituições e dos cursos de graduação, utilizando-se "procedimentos e critérios abrangentes dos diversos fatores que determinam a qualidade e a eficiência das atividades de ensino, pesquisa e extensão." Determinou, também, que um dos mecanismos integrantes do processo avaliativo fosse um exame de caráter nacional a ser aplicado anualmente a todos os concluintes desses cursos. Essa lei alterou dispositivos da Lei $\mathrm{n}$ 0 4.024, de 20 de dezembro de 1961, regulamentando as atividades do ConseIho Nacional de Educação. Além disso, dispõe, em seu artigo 3으, sobre o processo de avaliação no ensino superior:

\section{(...)}

Art. 3 - Com vistas ao disposto na letra "e" do § 2 o do Art. 9o da Lei n. 4.024, de 1961, com a redação dada pela presente Lei, o Ministério da Educação e do Desporto fará realizar avaliações periódicas das instituições e dos cursos de nível superior, fazendo uso de procedimentos e critérios abrangentes dos diversos fatores que determinam a qualidade e a eficiência das atividades de ensino, pesquisa e extensão.

$\S 1$ O Os procedimentos a serem adotados para as avaliações a que se refere o caput incluirão, necessariamente, a realização, a cada ano, de exames nacionais com bases nos conteúdos mínimos estabelecidos para cada curso, previamente divulgados e destinados a aferir os conhecimentos e as competências adquiridos pelos alunos em fase de conclusão dos cursos de graduação.

§ 20 O Ministério da Educação e do Desporto divulgará, anualmente, o resultado das avaliações referidas no caput deste artigo, inclusive dos exames previstos no parágrafo anterior, informando o desempenho de cada curso, sem identificar nominalmente os alunos avaliados.

$\S 3$ ㅇ realização de exame referido no § 1 o deste artigo é condição prévia para obtenção do diploma, mas constará do histórico escolar de cada aluno apenas o registro da data em que a ele se submeteu.

$\S 4$ ㅇ Os resultados individuais obtidos pelos alunos examinados não serão computados para sua aprovação, mas constarão de documento específico, emitido pelo Ministério da Educação e do Desporto, a ser fornecido exclusivamente a cada aluno.

§ 5o A divulgação dos resultados dos exames, para fins diversos do instituído neste artigo, implicará responsabilidade para o agente, na forma da legislação pertinente.

$\S 600$ aluno poderá, sempre que julgar conveniente, submeter-se a novo exame nos anos subseqüentes, fazendo jus a novo documento específico.

\footnotetext{
Refere-se ao Sistema Nacional de Avaliação da Educação Básica (Saeb), cuja primeira experiência foi realizada em 1989 , sendo desenvolvido nos anos subseqüentes com a participação das Secretarias Es taduais de Educação e estando, atualmente, sob coordenação do Inep.
} 
§7으 A introdução dos exames nacionais, como um dos procedimentos para avaliação dos cursos de graduação, será efetuada gradativamente, a partir do ano seguinte à publicação da presente Lei, cabendo ao ministro de Estado da Educação e do Desporto determinar os cursos a serem avaliados.

Art. 4응 Os resultados das avaliações referidas no $§ 1$ 으 do Art. 2ㅇ serão, também, utilizados pelo Ministério da Educação e do Desporto para orientar suas ações no sentido de estimular e fomentar iniciativas voltadas para a melhoria da qualidade do ensino, principalmente as que visem à elevação da qualificação dos docentes.

O exame instituído pela nova lei não era, portanto, o único instrumento previsto para a avaliação dos cursos de graduação. Os demais instrumentos possíveis precisavam ser desenvolvidos. Desencadeou-se, a partir daí, uma discussão em torno da construção do processo avaliativo, que culminou na edição do Decreto no 2.026, de 10 de outubro de 1996, que estabelece procedimentos para todo o processo de avaliação dos cursos e instituições de ensino superior. No que se refere especificamente ao ENC, assim dispõe o Artigo 50:

\section{(...)}

Art.5 $\mathrm{A}$ avaliação dos cursos de graduação far-se-á pela análise de indicadores estabelecidos pelas Comissões de Especialistas de ensino e levará em consideração os resultados do Exames $\mathrm{Na}$ cional de Cursos e os indicadores mencionados no Art. 3o, adequadamente adaptados para o caso.

Parágrafo único. A avaliação dos cursos de graduação conduzida pelas Comissões de Especialistas, designadas pela SESu, será precedida de análise abrangente da situação das respectivas áreas de atuação acadêmica ou profissional, quanto ao domínio do estado da arte na área, levando em consideração o contexto internacional e o comportamento do mercado de trabalho nacional.

O decreto foi editado pouco menos de um ano após a Lei no 9.131/95, que estabeleceu procedimentos para o processo de avaliação dos cursos e instituições de ensino superior, no qual se acha inserido o ENC.

A nova Lei de Diretrizes e Bases da Educação Nacional (LDB) - Lei no 9.394, de 20 de dezembro de 1996, veio reafir- mar as determinações da Lei no 9.131/95, incumbindo a União de avaliar todos os cursos e instituições de ensino superior e tornando obrigatório, em seu Art. 46, o reconhecimento periódico dos cursos de graduação, subsidiado por um processo prévio de avaliação externa:

(..)

Art. 46 A autorização e o reconhecimento de cursos, bem como o credenciamento de instituições de educação superior, terão prazos limitados, sendo renovados, periodicamente, após processo regular de avaliação.

$\S 1$ 을ós um prazo para saneamento de deficiências eventualmente identificadas pela avaliação a que se refere este artigo, haverá reavaliação, que poderá resultar, conforme o caso, em desativação de cursos e habilitações, em intervenção na instituição, em suspensão temporária de prerrogativas da autonomia ou em descredenciamento.

$\S 2$ ○ No caso de instituição pública, o Poder Executivo responsável por sua manutenção acompanhará o processo de saneamento e fornecerá recursos adicionais, se necessários, para a superação das deficiências.

\section{ENC como parte de um Sistema Nacional de Avaliação do Ensino Superior}

O sistema em desenvolvimento está se utilizando, além de informações do Censo do Ensino Superior, realizado pelo Serviço de Estatísticas Educacionais (Seec), absorvido pelo Inep, de três ações paralelas e complementares de avaliação do ensino de graduação:

a) o ENC - que visa construir mais um indicador da qualidade do ensino nos cursos de graduação, complementando avaliações mais abrangentes das instituições e cursos de nível superior;

b) a avaliação das condições de oferta dos cursos por área de conhecimento, efetuada por comissões de especialistas da SESu, as quais devem integrar os indicadores de insumos e de eficiência com os resultados do ENC;

c) o fomento às atividades de avaliação institucional.

O ENC verifica a aquisição de conhecimentos e habilidades básicas dos grupos de concluintes dos cursos de graduação, 
qualquer que seja sua inserção social ou geográfica.

Envolvendo todo o universo dos formandos de cada curso de graduação avaliado, o resultado do Exame produz dados agregados por escola, esfera administrativa, município, estado, região, segundo diferentes tópicos avaliados. Dessa forma, são construídos referenciais que permitem a definição de ações voltadas para a melhoria da qualidade dos cursos, por parte de professores, técnicos, dirigentes e autoridades educacionais.

O resultado do Exame tem um papel complementar e deve ser associado aos resultados de um conjunto mais amplo de dados - obtidos pelas comissões de especialistas da SESu, pelo Paiub e pelo Seecque compõem o processo avaliativo, possibilitando a formulação de uma adequada política para ensino superior.

As comissões de especialistas da SESu realizam um trabalho permanente, e necessariamente lento e complexo, que envolvem, além da análise de indicadores, visitas in loco ao conjunto de instituições brasileiras que oferecem cursos na área de cada comissão. Esse trabalho inclui:

- levantamento do "estado da arte" em cada área de ensino, avaliando as deficiências apresentadas em termos das especialidades desenvolvidas e fazendo comparações com o desenvolvimento internacional do ensino das diferentes disciplinas;

- análise do projeto pedagógico do curso, da sua estrutura curricular, da infraestrutura disponível, da qualificação do corpo docente, das taxas de repetência e evasão e do desenvolvimento de atividades de pesquisa;

- avaliação da qualidade dos cursos oferecidos por diferentes instituições, utilizando o conjunto dos indicadores de insumos e dos resultados do ENC;

- avaliação dos pedidos de criação de novos cursos, estabelecendo critérios para sua aprovação, tendo em vista a necessidade de assegurar um padrão mínimo de qualidade.

A avaliação institucional, por sua vez, conjuga a auto-avaliação com a avaliação externa, integra os resultados dos demais processos avaliativos e utiliza indicadores gerais referentes à qualificação e às condições de trabalho do corpo docente e à adequação da infra-estrutura disponível. Além disso, leva em consideração a heterogeneidade das instituições, valorizando sua capacidade de respostas às necessidades da sociedade na qual se insere e respeitando as vocações diferenciadas de cada uma delas.

O processo de avaliação institucional compreende:

- um processo prévio de auto-avaliação, que fundamente um projeto institucional (a exemplo do que acontece no Paiub);

- análise dos indicadores institucionais, entre os quais: qualificação e regime de trabalho do corpo docente, infraestrutura, número de alunos de graduação e de pós-graduação, número e tipo de cursos oferecidos na graduação e na pósgraduação, organização interna e produção científica;

- análise dos resultados dos demais processos avaliativos (pesquisa, pós-graduação, ensino de graduação) que serão utilizados como indicadores de qualidade;

- relevância das atividades de extensão no contexto regional e nacional;

- análise da compatibilidade entre os indicadores e o projeto institucional.

O Exame, portanto, não é, e nem pode ser, o único instrumento de avaliação do ensino superior, pois essa avaliação tem múltiplas facetas e dispõe de múltiplos instrumentos. A própria Lei no 9.131/95 diz que os procedimentos de avaliação das instituições e cursos de nível superior "incluirão" exames nacionais. É um instrumento perfeitamente capaz de contribuir para retratar de maneira eficiente o tipo de formação que está sendo proporcionado aos nossos estudantes pelas nossas instituições de ensino superior.

Alegar, para se destruir a validade do ENC, que uma única prova não pode medir um processo que durou quatro anos ou mais não é pertinente. Em primeiro lugar, nega-se a tradição ocidental de se realizarem exames ou provas em diversos momentos da vida acadêmica e mesmo em diversas etapas do exercício profissional. Tais instrumentos têm sido utilizados não apenas para a avaliação do aluno, mas também do processo de ensino aprendizagem. Esquece-se que a "prova" não vai medir o processo complexo vivenciado numa instituição de ensino superior. Este já foi devidamente avaliado autonomamente pela instituição e pelos professores que aprovaram ou reprovaram seus alunos em inúmeras tarefas. O que se deseja verificar é se, ao final do curso, aquele grupo 
de alunos demonstra conhecimentos atualizados na sua área, além de competências e habilidades que permitam enfrentar os desafios apresentados pelo contexto social em constante mutação, no qual estão inseridos.

\section{0 processo de implantação}

O processo de implantação do programa de avaliação dos cursos de graduação foi rápido. O "Provão", como se tornou popularmente conhecido o ENC, foi aplicado pela primeira vez para as áreas de Administração, Direito e Engenharia Civil, em 1996, menos de um ano após a entrada em vigor da Lei $n=9.131$. A escolha desses cursos, como os pioneiros dentro desse novo processo de avaliação, deu-se com o apoio dos respectivos conselhos profissionais, associações de ensino e professores ligados a essas áreas.

Desde 1996, o ENC tem avançado em termos de número de cursos abrangidos e de graduandos examinados (ver Tabelas 1 e 2, a seguir), bem como de aperfeiçoamento da metodologia empregada. $\mathrm{E}$, pois, um sistema avaliativo em construção, sendo importante destacar que os aperfeiçoamentos não são fruto apenas da contribuição de especialistas, mas também, e poder-se-ia dizer fundamentalmente, de estudantes, professores e gestores das instituições. Essa contribuição se dá através de consultas, questionários e sondagens efetuadas em diversos momentos da avaliação.
Os três cursos que iniciaram o processo em 1996 passaram a seis em 1997 e a dez em 1998, somando-se, em 1999, outros três, a saber: 1999);

- Administração (1996, 1997, 1998 e

- Comunicação Social - habilitação Jornalismo (1998 e 1999);

- Direito (1996, 1997, 1998 e 1999);

- Economia (1999);

- Engenharia Civil (1996, 1997, 1998 e 1999);

- Engenharia Elétrica (1998 e 1999);

- Engenharia Mecânica (1999);

- Engenharia Química (1997, 1998 e 1999);

- Letras - habilitações em: a) Língua Portuguesa e respectivas literaturas; b) Línguas Portuguesa e Estrangeira Moderna e respectivas literaturas; c) Línguas Portuguesa e Clássica e respectivas literaturas (1998 e 1999);

- Matemática, incluindo Ciências - habilitação plena em Matemática (1998 e 1999);

- Medicina (1999);

- Medicina Veterinária (1997, 1998 e 1999);

- Odontologia (1997, 1998 e 1999).

Nos cursos em que ocorreu a primeira edição do ENC (Administração, Direito e Engenharia Civil), o número de provas em branco caiu de 11,7\%, em 1996, para 2,2\% em 1997, e 1,3\% em 1998. Entre os cursos avaliados a partir do segundo Exame (Engenharia Química, Medicina Veterinária e Odontologia), o número de provas em bran-

Tabela 1 - Número de cursos participantes do ENC (1996/1997/1998), por área

\begin{tabular}{lrrrrr|r|c}
\multicolumn{1}{c|}{ Área } & $\mathbf{1 9 9 6}$ & $\mathbf{1 9 9 7}$ & $\begin{array}{c}\text { Variação } \\
\mathbf{1 9 9 6 / 1 9 9 7} \\
\%\end{array}$ & $\mathbf{1 9 9 8}$ & $\begin{array}{c}\text { Variação } \\
\mathbf{1 9 9 7 / 1 9 9 8} \\
\%\end{array}$ & $\begin{array}{c}\text { Variação } \\
\mathbf{1 9 9 6 / 1 9 9 8} \\
\%\end{array}$ \\
\hline Administração & 335 & 354 & 5,7 & 391 & 10,5 & 16,7 \\
Direito & 179 & 196 & 9,5 & 212 & 8,2 & 18,4 \\
Engenharia Civil & 102 & 106 & 3,9 & 110 & 3,8 & 7,8 \\
Engenharia Química & - & 44 & - & 47 & 6,8 & - \\
Medicina Veterinária & - & 37 & - & 39 & 5,4 & - \\
Odontologia & - & 85 & - & 86 & 1,2 & - \\
Engenharia Elétrica & - & - & - & 81 & - & - \\
Jornalismo & - & - & - & 84 & - & - \\
Letras & - & - & - & 369 & - & - \\
Matemática & - & - & - & 291 & - & - \\
Total & $\mathbf{6 1 6}$ & $\mathbf{8 2 2}$ & $\mathbf{3 3 , 4}$ & $\mathbf{1 . 7 1 0}$ & $\mathbf{1 0 8 , 0}$ & $\mathbf{1 7 7 , 6}$
\end{tabular}


Tabela 2 - Número de presentes ao ENC (1996/1997/1998), por área

\begin{tabular}{|c|c|c|c|c|c|c|}
\hline Área & 1996 & 1997 & $\begin{array}{c}\text { Variação } \\
\text { 1996/1997 } \\
\%\end{array}$ & $\begin{array}{c}\text { Variação } \\
1998\end{array}$ & $\begin{array}{c}\text { Variação } \\
\text { 1997/1998 } \\
\%\end{array}$ & $\begin{array}{c}\text { Variação } \\
\text { 1996/1998 } \\
\%\end{array}$ \\
\hline Administração & 24.948 & 31.446 & 26,0 & 36.098 & 14,8 & 44,7 \\
\hline Direito & 26.209 & 36.682 & 40,0 & 41.158 & 12,2 & 57,0 \\
\hline Engenharia Civil & 4.380 & 5.874 & 34,1 & 5.400 & $-8,1$ & 23,3 \\
\hline Engenharia Química & & 1.643 & - & 1.417 & $-13,8$ & - \\
\hline Medicina Veterinária & . & 2.233 & - & 2.202 & $-1,4$ & - \\
\hline Odontologia & - & 7.698 & - & 7.488 & $-2,7$ & - \\
\hline Engenharia Elétrica & - & - & - & 4.271 & - & - \\
\hline Jornalismo & - & - & - & 4.188 & - & - \\
\hline Letras & - & - & - & 16.604 & - & - \\
\hline Matemática & - & - & - & 7.997 & - & - \\
\hline Total & 55.537 & 85.576 & 54,1 & 126.823 & 48,2 & 128,4 \\
\hline
\end{tabular}

Fonte: DAES/INEP/MEC - ENC 98

co baixou de 2,1\% em 1997 para 1,8\% em 1998. Dentre os quatro cursos avaliados pela primeira vez em 1998 (Engenharia Elétrica, Jornalismo, Letras e Matemática), $4,9 \%$ dos graduandos deixaram de responder à prova. A Tabela 3 , abaixo, apresenta os percentuais de provas em branco em relação ao número de presentes, no ENC (1996/1997/1998).

Desde o início do processo de implantação do Exame, têm sido realizados diversos encontros e debates com professores, dirigentes de instituições de ensino superior (IES) e estudantes, no sentido de ampliar a discussão com a comunidade acadêmica sobre a importância desse instrumento de avaliação, trocar idéias e colher sugestões. Simultaneamente, a Secretaria de Ensino Superior do MEC (SESu), por intermédio de suas comissões de especialistas de ensino, desenvolve um outro instrumento - a avaliação das condições de oferta dos cursos - com características de avaliação do processo de ensino e com abrangência capaz de incorporar outros aspectos relevantes, tais como: o projeto didático-pedagógico do curso; a administração acadêmica; o perfil do corpo docente (titulação, regime de trabalho, experiência profissional) e sua política de qualificação; produção acadêmica; infra-estrutura física; bibliotecas e laboratórios.

Tabela 3 - Provas em branco em relação ao número de presentes ao $\operatorname{ENC}(1996,1997$ e1998)

\begin{tabular}{l|r|r|c}
\multicolumn{1}{c|}{ Área } & \multicolumn{3}{c}{ \% Provas em branco/presentes } \\
& $\mathbf{1 9 9 6}$ & $\mathbf{1 9 9 7}$ & $\mathbf{1 9 9 8}$ \\
Administração & 8,4 & 0,4 & 0,4 \\
Direito & 11,4 & 1,9 & 1,3 \\
Engenharia Civil & 32,1 & 13,9 & 6,5 \\
Engenharia Química & - & 6,6 & 8,0 \\
Medicina Veterinária & - & 2,3 & 3,4 \\
Odontologia & - & 1,0 & 0,2 \\
Engenharia Elétrica & - & - & 4,0 \\
Jornalismo & - & - & 10,6 \\
Letras & - & - & 4,5 \\
Matemática & - & - & 3,2 \\
Total & $\mathbf{1 1 , 7}$ & $\mathbf{2 , 2}$ & $\mathbf{2 , 1}$
\end{tabular}


Concretamente, pode-se dizer que a partir dos resultados do primeiro ENC, divulgados em abril de 1997, foi possível observar uma grande movimentação nas IES em busca da melhoria das condições de ensino, resultando, por exemplo, na preocupação em qualificar melhor o corpo docente e em equipar melhor laboratórios e bibliotecas.

Essa movimentação provocada pelo ENC e a adoção de medidas efetivas para um ensino de graduação com melhor qualidade têm resultado no crescimento, a cada ano, do apoio que entidades ligadas, direta ou indiretamente, à educação superior dispensam ao projeto. Além disso, na esteira dessa movimentação em prol de um ensino superior com mais qualidade, o processo de coleta de dados estatísticos do ensino superior, sob a responsabilidade do Instituto Nacional de Estudos e Pesquisas Educacionais (Inep), foi reformulado e o Paiub, coordenado pela SESu, está sendo reestruturado, com o objetivo de melhor integrá-los ao sistema de avaliação do ensino superior brasileiro.

A cada ano, vai-se ampliando o número e melhorando a qualidade das informações sobre os cursos de graduação, possibilitando um conhecimento cada vez mais amplo e um diagnóstico cada vez mais preciso da realidade de cada curso e do sistema de ensino superior de um modo geral.

\section{Sistemática}

Todos os alunos que estão em vias de concluir o curso de graduação durante o ano letivo devem prestar o Exame, que é condição obrigatória para a obtenção do registro do diploma, independentemente do regime escolar em que esteja matriculado (semestral ou anual). A inscrição do graduando é de responsabilidade exclusiva de sua instituição de ensino. Mas cada graduando deve procurar a instituição para atualizar os seus dados pessoais. As instituições devem sempre realizar as inscrições dos prováveis graduandos do ano letivo em curso até setenta dias antes do Exame. Os procedimentos e instrumentos para a realização das inscrições são enviados às instituições, pelo Inep, em dezembro. O Exame é aplicado anualmente, entre maio e junho. A data é definida um ano antes, por meio de portaria do ministro de Estado da Educação, assim como os cursos a serem avaliados.

Os objetivos, os conteúdos e todas as demais especificações necessárias à elaboração das provas que compõem o Exame têm por base as atuais diretrizes e conteúdos curriculares, bem como as exigências decorrentes dos novos cenários geopolíticos, culturais e econômicos que se esboçam. Os conteúdos do Exame são definidos por uma comissão específica para cada curso, considerando a diversidade dos elementos compartilhados pelos projetos pedagógicos das instituições.

Essas comissões de cursos, compostas por especialistas de notório saber, atuantes na área, são constituídas mediante portaria ministerial após consulta às comissões de especialistas de ensino da SESu, ao Crub, às associações nacionais de ensino e aos conselhos federais de profissões regulamentadas, que orientam o processo de avaliação do qual o ENC é parte.

As comissões de curso desempenham um papel fundamental na implementação do Exame. Inicialmente elas se reúnem de setembro a fevereiro, para definir as diretrizes do ENC: os objetivos específicos para o Exame de cada curso; o perfil desejado do graduando; as habilidades e os conteúdos que os graduandos de cada curso devem ter desenvolvido no decorrer de sua vivência acadêmica, além do formato de uma prova que seja capaz de expressar as expectativas subjacentes a essas diretrizes.

Como subsídio ao trabalho das comissões, as instituições de ensino enviam à Diretoria de Avaliação e Acesso ao Ensino Superior (Daes), do Inep, sugestões de habilidades e conteúdos a serem verificados no Exame, além das características do perfil do profissional que cada curso pretende estar formando. Portarias ministeriais fixam as determinações traçadas pelas comissões. São definidas, para as bancas responsáveis pela elaboração e correção das provas, orientações detalhadas de como devem ser as provas, o número e o tipo de questão a serem utilizados para verificar as habilidades e os conteúdos estabelecidos. Após o Exame, as comissões participam da definição final do padrão de respostas esperado das questões discursivas das provas. 


\section{Questionário-Pesquisa}

O Exame é precedido de um questionário-pesquisa enviado a todos os graduandos inscritos, destinado a ouvir-lhes a opinião sobre o curso e a instituição de ensino superior que freqüentaram, sobre os professores que tiveram durante o curso e sobre suas perspectivas para o futuro, além de traçar-lhes o perfil socioeconômico e cultural. As respostas a essa pesquisa são entregues pelos estudantes no dia do Exame. Em 1998, foram recolhidas 116.114 folhas de respostas, o que correspondeu a $91,6 \%$ dos presentes. Os resultados da pesquisa, resumidos por área, fazem parte do Relatório-Síntese e podem ser encontrados no final dos anexos específicos de cada área, junto com a análise das provas.

\section{Provas}

As provas dos cursos avaliados são elaboradas e corrigidas por bancas de cujos trabalhos, em 1998, participaram 203 professores, mestres e doutores, com vasta experiência no magistério de graduação, provindos de diferentes regiões do País. Para coordenar o trabalho dessas bancas, preparar e aplicar as provas, coordenar o processo de correção, tabular os resultados e fazer uma análise preliminar dos dados obtidos, tem sido contratado, nos últimos anos, após processo de licitação, um consórcio formado pelas Fundações Cesgranrio e Carlos Chagas.

No dia do Exame de 1998, após a prova, foi feita uma pesquisa amostral com $10 \%$ dos alunos presentes que foram convidados a responder a dez questões, com o objetivo de colher impressões sobre a prova que acabara de ser realizada e sobre a importância do Exame. Um total de 9.426 alunos $(7,5 \%$ do total) dispôs-se a participar da pesquisa. De um modo geral, consideraram que as respectivas provas não haviam sido difíceis e que quatro horas haviam sido suficientes para resolver todas as questões propostas.

$\mathrm{Na}$ semana seguinte à aplicação do Exame, são enviados a todos os coordenadores de curso questionários de avaliação das provas, com a solicitação de que sejam consultados os demais professores do curso. Alguns cursos fazem a consolidação dessa análise conjunta em uma res- posta única; outros enviam também as avaliações individuais dos professores. Assim, em 1998, um total de 756 coordenadores de cursos e professores responderam à solicitação. A maioria dos que responderam ao referido questionário considerou o Exame adequado aos objetivos propostos, aos conteúdos e às habilidades definidas. Essas apreciações foram sistematizadas e analisadas pelas comissões de curso, quando de sua avaliação das provas e dos resultados do ENC 98.

Todas essas análises são encaminhadas às bancas de especialistas responsáveis pela elaboração das provas, com vistas a garantir a contínua revisão, o aperfeiçoamento e a adequação dos instrumentos a serem utilizados nos próximos Exames.

\section{Relatórios}

O ENC não se esgota na divulgação dos resultados. Concebido como instrumento de avaliação num processo de melhoria da qualidade do ensino superior e de democratização da gestão desse nível de educação, não poderia deixar de fornecer elementos para que as instituições, os alunos e a sociedade como um todo possam agir no sentido do aperfeiçoamento dos cursos de graduação. Esses elementos são disseminados por meio dos seguintes produtos:

\section{Relatório-Síntese}

Esse relatório é elaborado após a realização das provas. Ele sintetiza os trabalhos e resultados do ENC e traz informações que integram o Sistema Nacional de Avaliação do Ensino Superior, consolidando-se como fonte permanente de consulta para as instituições de ensino superior, especialistas e para a sociedade em geral. Os dados de cada ano são acompanhados de outras informações dos cursos avaliados, que podem oferecer um quadro mais abrangente para análise. Assim sendo, para cada área é apresentado, no final do capítulo correspondente, um quadro-resumo, com as seguintes informações, relativas ao ENC do ano de referência e aos Exames anteriores, quando for o caso:

a) do conceito atribuído aos cursos no Exame; 
b) da evolução da média padronizada dos cursos, de um Exame para o outro;

c) do índice de participação, isto é, do percentual de graduandos presentes que responderam à prova;

d) do conceito atribuído à titulação do corpo docente em exercício no curso;

e) do conceito atribuído ao regime de trabalho do corpo docente em exercício no curso;

f) da relação candidato-vaga oferecida nos vestibulares dos anos de ingresso dos graduandos submetidos ao Exame;

g) dos conceitos atribuídos pela Fundação Capes aos cursos de pós-graduação oferecidos pela instituição de ensino na mesma área do curso avaliado.

\section{Anexos}

Elaborados para cada área do Exame, contêm as provas, os gabaritos das questões de múltipla escolha e as grades de respostas das questões discursivas e a análise técnica das provas. Contêm também os questionários-pesquisa completos, com a respectiva análise.

\section{Relatório da instituição de ensino superior}

Como acontece a cada Exame, paralelamente ao Relatório-Síntese, as instituições de ensino superior, cujos cursos foram avaliados, recebem um relatório individual, com dados estatísticos gerais do Brasil, da região e do estado a que pertencem, e com os resultados do seu curso: a média do seu grupo de graduandos em cada questão discursiva, o percentual de acerto em cada questão de múltipla escolha e o percentual de respostas em cada alternativa do questionáriopesquisa preenchido por seus alunos. No caso de cursos já avaliados em mais de um Exame, são apresentados também os resultados dos Exames anteriores. Esse relatório oferece valiosas informações que podem contribuir para que se desencadeiem diversas ações voltadas para o aprimoramento dos respectivos cursos. Por ser a melhoria da qualidade do ensino o principal objetivo da avaliação, o relatório da instituição representa uma peça fundamental para que o Exame atinja sua meta. Com a finalidade de discutir as possibilidades de utilização dessas informações, a Daes/Inep tem realizado diversos encontros em instituições de ensino de todo o País.

\section{Boletim individual de desempenho}

O boletim individual de desempenho contém, além da média obtida pelo graduando em cada uma das partes da prova e a sua média global, os dados do Brasil, da região e do estado, possibilitando situar o desempenho individual em relação a cada um desses grupos. Conforme determina a Lei no $9.131 / 95$, o boletim é enviado exclusivamente a cada graduando, no endereço informado quando de sua inscrição no Exame.

Os relatórios do ENC são encaminhados pelo Inep à SESu, órgão do MEC, responsável pela política e pela gestão do sistema nacional de ensino de graduação. A SESu utiliza os resultados do Exame para orientar suas ações no sentido de estimular e fomentar iniciativas voltadas para a melhoria da qualidade do ensino. A efetiva qualidade do ensino passa obrigatoriamente pela adequada utilização de mecanismos institucionais disponíveis, sendo um deles a deliberação do Conselho Nacional de Educação (CNE) quanto ao reconhecimento de cursos e habilitações, ao credenciamento e ao recredenciamento periódico das instituições de ensino superior. Para a execução desse trabalho, o CNE conta com os relatórios das avaliações dos cursos, além de outros dados decorrentes de análises de documentações e de acompanhamentos. Os relatórios das avaliações fornecem subsídios para que o CNE desempenhe, com maior segurança, as suas atribuições legais, zelando pela qualidade do ensino brasileiro.

\section{Os resultados e sua utilização}

Os resultados do ENC têm confirmado a vantagem das instituições públicas estaduais e federais sobre as instituições privadas, em que pese o fato de terem menos de um terço dos cursos avaliados e do total de graduandos presentes ao exame. As instituições públicas estaduais destacamse das demais, tendo o maior número de cursos com conceitos A e B em Direito, 
Engenharia Civil, Engenharia Elétrica, Engenharia Química, Jornalismo, Medicina Veterinária e Odontologia. As instituições públicas federais tiveram o melhor desempenho em Administração, Letras e Matemática. Os cursos mantidos por instituições privadas estão melhorando seu desempenho no Provão, mas ainda estão longe de atingir a performance das instituições públicas estaduais e federais. Os cursos mantidos pelas instituições públicas municipais repetiram em 1998 o fraco desempenho das duas primeiras avaliações.

A evolução positiva da qualidade do ensino superior nacional ficou comprovada pelo fato de que: $1^{\circ}$ ) as instituições, em geral, tiveram um desempenho superior ao de exames anteriores; $2^{\circ}$ ) aumentou a preocupação das instituições com a qualificação dos professores, tanto em termos de pós-graduação em nível de mestrado e doutorado como de aumento da dedicação ao trabalho em sala de aula; 3 의 pressionadas pelos alunos e pela sociedade, as instituições estão se mobilizando para melhorar as condições de oferta dos cursos; 4 ) ) houve queda do boicote e do número de provas em branco; 5ㅇ) o exame deu visibilidade às instituições que possuem cursos com melhores conceitos; e 6으 os coordenadores de cursos estão muito mais empenhados e dispostos a colaborar com as comissões de cursos na formulação das diretrizes do Exame.

O ENC, tal como foi aplicado nos primeiros anos, produziu efeitos positivos palpáveis em termos de elevação da qualidade do ensino superior brasileiro, especialmente nas instituições privadas. Tais resultados tiveram grande repercussão junto à mídia e, conseqüentemente, junto à sociedade como um todo. Não são, entretanto, os elementos mais importantes para o desenvolvimento profissional dos estudantes ou para o aperfeiçoamento do ensino superior brasileiro.

A avaliação em desenvolvimento no ENC pode ser caracterizada como referenciada a "normas" e não a "critérios". Isso significa que o desempenho é medido em comparação ao desempenho dos outros alunos e não em relação ao domínio de conteúdos específicos. A modalidade adotada oferece rica informação para propósitos comparativos, principalmente considerando o fato de que não se tem conhecimento prévio do que é realmente ensinado.
O Exame, na perspectiva da avaliação por norma, constitui-se um mecanismo subsidiário ao processo de ensino-aprendizagem, evitando que se transforme em instrumento coercitivo sobre o currículo pleno desenvolvido pela instituição, preservando a sua autonomia didático-científica. Não existe, portanto, definição prévia de "padrões mínimos de desempenho", mas os resultados permitem que o desempenho do conjunto de graduandos (em cada questão ou na média global) seja comparado ao desempenho de outros grupos de graduandos. Da mesma forma, cada graduando pode visualizar comparativamente o seu desempenho pessoal em relação aos demais da mesma instituição ou de outras instituições, por exemplo.

As provas, normatizadas pelos professores das comissões de curso, não são um elemento externo e estranho à vida acadêmica. Pelo contrário, resultam e retroalimentam os projetos e as práticas didático-pedagógicas. Isso se deve ao fato de que as instituições que oferecem os cursos a serem avaliados são solicitadas a fornecer informações sobre o "projeto pedagógico" efetivamente trabalhado, além de sugestões e outros subsídios. Esse material é consolidado pelo Inep e utilizado como referência pelos membros das comissões.

Como as comissões analisam as provas logo após a realização do Exame, recebendo também as críticas e sugestões dos coordenadores e professores dos cursos avaliados, colhidas de forma sistemática pelo Inep, têm-se uma série de elementos que são consolidados para observação tanto pela própria comissão na preparação do Exame seguinte, como para a orientação da banca que elabora e corrige as provas. Garante-se, portanto, um processo de participação sistemática dos cursos e instituições, bem como de retrolimentação contínua, dentro de cada ciclo avaliativo.

A consciência da necessidade de se preparar adequadamente, nos cursos de graduação, profissionais e cidadãos para o século XXI tem pautado o trabalho dessas comissões de cursos. Além disso, esse trabalho procura sempre estar sintonizado com as necessidades nacionais e tendências mundiais do ensino na área. ${ }^{2}$

Embora a elaboração, a aplicação e a correção das provas estejam a cargo de entidades contratadas pelo Inep, essas en-

\footnotetext{
2 Tome-se, como exemplo, o perfil e habilidades definidos pelas comissões de curso.
} 
tidades seguem diretrizes precisas e instruções detalhadas das comissões de cursos, e as bancas examinadoras (elaboradoras dos instrumentos) são compostas de docentes do ensino superior. Isso reforça a vinculação entre o Exame e a realidade didático-pedagógica dos cursos examinados e o processo avaliativo, agilizando e aprofundando o movimento de retroalimentação das instituições a respeito das providências a serem adotadas, tendo em vista a melhoria da qualidade do ensino.

Os graduandos inscritos no Exame respondem a um questionário - como já mencionado anteriormente - para levantar informações sobre as condições institucionais de ensino vivenciadas, bem como traçar o perfil socioeconômico e cultural, cuja avaliação fornece dados importantes para esclarecer muitas concepções a respeito do estudante que consegue concluir um curso de graduação. Tornase possível, assim, revisar com transparência e objetividade os sistemas de acesso vigentes, a concessão de bolsas, a organização do tempo pedagógico durante o curso e a construção de base para o acompanhamento dos egressos pelas instituições (seja como forma de receber subsídios para a reformulação das propostas pedagógicas dos cursos, seja para a mobilização visando à obtenção de recursos, etc.).

Exames e provas aplicadas universalmente ou em amostras de estudantes têmse mostrado internacionalmente como adequados para implementar programas de reforma curricular e de elevação da qualidade do ensino em seus diversos níveis. $\mathrm{O}$ ENC conta com a participação da comunidade acadêmica interessada em mudar o estado atual do ensino superior brasileiro e consciente de que esse não pode ser o único instrumento de avaliação, mas é, mesmo assim, um instrumento indispensável para aferir os conhecimentos e as habilidades e competências que os cursos de graduação estão proporcionando.

Da mesma forma que os demais processos de avaliação, o Exame:

a) não está vinculado a mecanismos de punição ou premiação, mas sim ao fornecimento de subsídios para a tomada de decisões, o planejamento e a administração das instituições, capazes de induzir ao seu aprimoramento, bem como de corrigir eventuais falhas; b) catalisa no curso a reflexão sobre seus objetivos, sua realidade atual e suas possibilidades futuras, de forma a induzir à construção de políticas estratégicas institucionais;

c) possibilita o acompanhamento da evolução do curso, revelando o grau de eficácia das ações adotadas.

d) possibilita, também, com a continuidade do processo, a verificação da confiabilidade dos instrumentos e dos resultados, além de consolidar a cultura da avaliação.

Alguns efeitos positivos dos primeiros resultados do ENC já podem ser constatados. A formação de uma massa crítica de dados já é uma realidade após a série de edições das provas e dos questionários-pesquisa. Suas funções e procedimentos certamente evoluirão e se transformarão. No momento, contudo, o Exame e os demais elementos avaliativos já desempenham um papel transformador para dezenas de instituições e cursos, além de recuperar a missão do ensino superior como instrumento de democratização do conhecimento. Desde já, entretanto, as repercussões do ENC sobre o ensino superior brasileiro são apreciáveis e podem ser sintetizadas da seguinte forma:

Repercussões junto às instituições de ensino

As resistências ao Exame, manifestadas por muitos dirigentes no início de sua implantação, estão sendo substituídas por esforços que visam a encontrar alternativas para a melhoria do ensino de graduação. Este é o principal objetivo do ENC. Entre esses esforços, pode-se citar:

- reformulação nos parâmetros de contratação de docentes (salário, regime de trabalho);

- incentivo à atualização e, em alguns casos, à freqüência a cursos que permitem a titulação acadêmica stricto sensu;

- busca de professores mais qualificados, seja para gerir os cursos, seja para a atividade de ensino e orientação pedagógica;

- investimento na avaliação institucional, tomando os resultados do Exame como um dos elementos fundamentais do processo de avaliação institucional;

- entendimento do processo de avaliação como prática que deve estar presente no cotidiano da instituição;

- entendimento de que a avaliação é uma forma de a sociedade acompanhar as 
limitações, os esforços e os avanços da universidade brasileira (pública ou privada).

Em suma, a administração pedagógica e institucional tem agora referenciais nos relatórios do Exame, para levantar questões específicas referentes a cada curso avaliado e à sua própria instituição. Esses resultados contribuem para um processo de avaliação permanente das propostas, dos projetos e das práticas pedagógicas vigentes na instituição de ensino superior. Muitas instituições também têm percebido que a busca de superação das limitações estruturais ao longo do curso é a única garantia de melhoria dos resultados obtidos pelos seus graduandos. A alternativa de "exames simulados" ou atividades preparatórias emergenciais esporádicas somente com os graduandos que irão prestar o Exame tem se mostrado insuficiente para a obtenção de desempenho consistente.

A fim de aprimorar, a cada ano, a metodologia, os instrumentos e a divulgação dos resultados do ENC, a partir de 1999 serão promovidos seminários com a participação das comissões de cursos e dos responsáveis acadêmicos pelos cursos de graduação, para debater mais amplamente o Exame no atual estágio de implementação, avaliando seus procedimentos, resultados e seu potencial como instrumento de avaliação e melhoria da qualidade do ensino superior.

Os seminários terão por objetivo:

1. analisar o ENC, no contexto do Sistema Nacional de Avaliação do Ensino Superior, a partir dos resultados de cursos com, pelo menos, dois anos dessa avaliação e analisar as potencialidades do ENC como elemento auxiliar na gestão do ensino, para subsidiar políticas comprometidas com a melhoria dos cursos de graduação;

2. discutir com os responsáveis acadêmicos pelos cursos das IES a utilização de resultados do ENC no desenvolvimento de ações que visem à melhoria da qualidade dos respectivos cursos;

3. colher subsídios para aprimorar a sistemática de planejamento e execução do ENC.

\section{Repercussões junto ao corpo docente}

Todos os coordenadores dos cursos avaliados têm sido solicitados a articular a participação dos professores no processo de avaliação, à medida que informam sobre o projeto pedagógico do curso; analisam e criticam os instrumentos utilizados; analisam os resultados do desempenho dos alunos nas diferentes matérias do curso e, por fim, propõem ações institucionais pertinentes. Há testemunhos de professores de que, em dezenas de instituições, a prioridade do ensino de graduação voltou a ser colocada no contexto da política institucional. Como nunca antes, os coordenadores de curso voltaram a se articular com os professores, visando à atualização de programas das disciplinas, à utilização apropriada do tempo pedagógico, à solicitação de bibliografia e equipamentos de infra-estrutura, etc.

Em muitas instituições, após a divulgação dos primeiros resultados, começaram a ser reformulados os contratos de trabalho, visando a uma melhor remuneração e a uma disponibilidade maior de tempo. Tem ocorrido também a procura, por parte dos professores, de oportunidades de qualificação e atualização acadêmica, bem como de oferta de condições para investimento em atividades de qualificação formal ou de simples atualização.

\section{Repercussões junto aos estudantes de graduação}

O resultado individual não interessa à avaliação pretendida com o ENC. Só pode ser fornecido "exclusivamente a cada aluno". Aquele que não estiver interessado em conhecer o seu resultado individual pode simplesmente abrir mão dessa prerrogativa. Mas tem permitido aos interessados a identificação da posição relativa quanto ao universo do seu curso, de uma forma objetiva, não mais apenas pela "imagem" da instituição em que está concluindo o curso. Tem sinalizado também para o estudante de que é indispensável a contrapartida de seu esforço pessoal ao longo do curso.

Em dezenas de instituições, os alunos dos cursos avaliados (principalmente após a divulgação dos resultados relativos aos três primeiros) têm se mobilizado para reivindicar ou buscar alternativas para a melhoria do ensino: atendimento integral de matérias previstas no currículo mínimo, mas não cobertas pelas disciplinas ministradas; contratação de professores necessários e qualificados; providência ou 
melhoria de itens básicos da infra-estrutura, etc.

Há testemunhos de estudantes relatando a efetiva melhoria no processo de ensino em muitas instituições, no último ano. As informações sobre o desempenho individual, encaminhadas exclusivamente ao estudante, têm se constituído elemento importante para a definição de estratégias para o seu próprio desenvolvimento profissional e pessoal.

\section{Repercussões junto aos órgãos públicos federais}

Os relatórios do ENC, por força de lei, devem ser encaminhados ao MEC. Assim, a SESu, órgão do MEC, deve obrigatoriamente levar em conta os resultados do Exame e de outros processos de avaliação, na formulação de políticas e na gestão do sistema nacional de ensino de graduação. Não seria inadequado que os setores interessados colaborassem com proposições ou reivindicações conseqüentes. Nesse sentido, a SESu tem utilizado os resultados na dinamização das suas comissões de especialistas (principalmente no caso dos primeiros cursos avaliados) e na reativação do Paiub. Prevê a utilização dos resultados do Exame como subsídios relevantes para a normatização de diversas ações, entre as quais se pode mencionar : a) definição dos procedimentos quanto às informações sobre condições de ensino-aprendizagem; b) autorização de novos cursos; c) credenciamento de faculdades integradas, faculdades, institutos superiores ou escolas superiores; d) credenciamento de centros universitários; e) autorização para funcionamento de cursos fora de sede em universidades; f) credenciamento de universidades.

Como decorrência da massa crítica de informações sobre o ensino de graduação, obtida a partir da implantação do sistema de avaliação, cabe destacar a decisão do MEC de iniciar imediatamente o processo de renovação do reconhecimento dos cursos superiores, conforme prevê a nova LDB, editando a Portaria no 755 , de 11 de maio de 1999.

Por meio dessa Portaria, o ministro da Educação, com fundamento no Art. 46 da Lei $n$ o 9.394/96, determinou à Secretaria de Educação Superior (SESu) que proce- da à renovação do reconhecimento dos cursos de graduação que tenham obtido conceitos $\mathrm{D}$ ou $\mathrm{E}$ em três avaliações consecutivas realizadas pelo ENC, como também daqueles que tenham obtido conceito $\mathrm{Cl}$ (Condições Insuficientes) em dois aspectos ou mais da avaliação das condições de oferta realizada por aquela Secretaria. O procedimento adotado para tanto é definido nos artigos 20 a 9 을 referida Portaria:

(...)

Art. 2으 A Secretaria de Educação Superior (SESu) designará os especialistas responsáveis pela verificação in loco de cada um dos cursos referidos no Art. 10, visando à elaboração de relatório de avaliação das condições de seu funcionamento.

Art. 3o A SESu encaminhará à Câmara de Educação Superior do Conselho Nacional de Educação, para deliberação, relatório técnico sobre a instituição responsável pelo curso, acompanhado da avaliação da equipe de especialistas e de outras informações relevantes para o processo de renovação do reconhecimento.

Parágrafo único. A deliberação da Câmara de Educação Superior poderá ser: a) favorável à renovação do reconhecimento, fixando o seu prazo de validade; b) desfavorável, com indicação de revogação do ato de reconhecimento do curso, observado o disposto no Art. 6‥

Art. 40 A homologação de deliberação favorável da Câmara de Educação Superior do Conselho Nacional de Educação resultará na expedição do ato de renovação do reconhecimento do curso e/ou habilitação, requisito necessário à outorga de diplomas. Art. 5o A homologação de deliberação desfavorável implicará a revogação do ato de reconhecimento do curso e em sua desativação.

Parágrafo único. A aplicação do disposto no caput importará na anulação do ato de autorização do respectivo curso, quando for o caso.

Art. 6o A Câmara de Educação Superior do Conselho Nacional de Educação, em parecer prévio à deliberação sobre a renovação do reconhecimento, poderá determinar à instituição, por intermédio da SESu, o cumprimento, no prazo máximo de 6 (seis) meses, de exigências com vistas ao saneamento de deficiências identificadas.

$\S 1$ C Cumpridas as exigências a que se refere o caput, a instituição solicitará à SESu nova visita da Comissão de Especialistas;

§ 2o A inobservância do prazo estabelecido no caput resultará na revogação do ato 
de reconhecimento do curso e sua desativação.

Art. 70 Os alunos dos cursos cujo reconhecimento não tenha sido renovado terão assegurado o direito à transferência para curso idêntico, em série ou período correspondente, em outra instituição.

Parágrafo único. Para fins do cumprimento do caput, a instituição fica obrigada a colocar à disposição do Ministério da Educação toda a documentação e registros acadêmicos dos alunos de cursos cuja renovação do reconhecimento tenha sido negada.

Art. 8 o No exercício de 1999, serão submetidos ao processo de renovação do reconhecimento a que se refere esta Portaria, os cursos de graduação em Administração, Direito e Engenharia Civil ministrados pelas instituições relacionadas, respectivamente, nos Anexos I, II e III desta Portaria.

Art. 9o Os cursos reconhecidos a partir da edição da Portaria Ministerial no 877/ 97 têm assegurado, para fins de renovação, o prazo estabelecido no ato legal de seu reconhecimento.

As decisões a respeito serão tomadas pela Câmara de Educação Superior do Conselho Nacional de Educação (CNE), com base na verificação in loco realizada por comissões de especialistas encarregadas de elaborar relatórios específicos para tal fim.

A SESu também tem utilizado os resultados como subsídios para a formulação de ações, no sentido de estimular e fomentar iniciativas voltadas para a melhoria da qualidade do ensino. Nesse caso, pode-se citar o Programa de Modernização e Qualificação do Ensino Superior (Pmoes), com plano de investimentos definido para 1997-1998, cujo objetivo é o "aprimoramento e desenvolvimento das atividades acadêmicas, com ênfase no ensino de graduação".

A efetiva melhoria da qualidade do ensino passa obrigatoriamente pela adequada utilização de mecanismos institucionais disponíveis, sendo um deles a deliberação do CNE quanto ao reconhecimento de cursos e habilitações e quanto ao credenciamento e ao recredenciamento periódico das instituições de ensino superior. Para a execução desse trabalho, o CNE conta com os relatórios das avaliações dos cursos, além de outros dados decorrentes de análises de documentações e de acompanhamentos. Os relatórios das avaliações, entre os quais está o do Exame, fornecerão subsídios para que o CNE desempenhe, com maior segurança, as suas atribuições legais, zelando pela qualidade do ensino brasileiro.

As considerações acima só poderão ser consolidadas com o tempo, à medida que o Exame se firmar como um dos instrumentos de avaliação externa, eficiente e confiável, e à medida que, dentro de uma série histórica, for possível avaliar a evolução dos cursos e das instituições de ensino superior brasileiras.

\section{Referências bibliográficas}

BELONI, Isaura. Democracia na universidade: democratização do acesso, da gestão e dos resultados. Educação Brasileira, Brasília, v. 8, n. 17, p. 57-102, 1986.

MAGGIE, Yvonne. Graduação e pós-graduação em Ciências Humanas: desafios e perspectivas. In: DISCUSSÃO da pós-graduação brasileira. Brasília : Capes, 1996. p. $19-28$.

PAUL, Jean Jacques, RIBEIRO, Zoya, PILATI, Orlando. As iniciativas e as experiências de avaliação de Ensino Superior: balanço crítico. In: DURHAM, Eunice R., SCHWARTZMAN, Simon (Org.). Avaliação do Ensino Superior. São Paulo : Editora da USP, 1992. p. 141-165. (Coleção Base, v. 2).

PORTO, Stella, VELLOSO, Marisa, PILATI, Orlando. Ensino público superior noturno e democratização. Revista Brasileira de Estudos Pedagógicos, Brasília, v. 69, n. 162 , p. 277-315, maio/ago., 1988. 
REFORMA Universitária: propostas e controvérsia. Brasília : Crub, 1987. 217 p. (Estudos e Debates, 13).

RIBEIRO, Sergio Costa et al. A relação pesquisa-ensino nas instituições de ensino superior. Revista Brasileira de Estudos Pedagógicos, Brasília, v. 67, n. 155, p. 5-51, jan./abr., 1986.

Ensino e/ou pesquisa: a teoria na prática é outra. Ciência Hoje, v. 4, n. 22 , p. 24-33, jan./fev., 1986.

ZUCCO, Cézar. Relação entre pós-graduação e graduação: a pós-graduação no contexto histórico-educacional. In: DISCUSSÃO da pós-graduação brasileira. Brasília : Capes, 1996. p. $79-90$.

Recebido em 10 de setembro de 1998.

Tancredo Maia Filho é diretor de Avaliação do Ensino Superior (Daes) do Inep.

Orlando Pilati é coordenador-geral de Estudos e Pesquisas da Daes/Inep.

Sheyla Carvalho Lira é coordenadora-geral do Exame Nacional de Cursos de Graduação da Daes/Inep.

\section{Abstract}

The paper establishes the National Course Examination as an evaluation instrument for higher education in Brazil. It describes the exam implementation process determining its legal frame. It also describes the examination application system, the tests and researchquestionaires involved and the way the results are organized, disseminated and utilized. It finally points out the exam's repercussion among learning institutions, teaching staff, students and government agencies.

Key-Words: National Course Examination; evaluation of higher education. 